\title{
Experimental Investigation of Shear Strength of Precast Pre-stresse Ribbed And Hollow Core Slab Units
}

altuhami aaltuhami, Osman Shallan, Abdel Aziz Abdel Aziz, Sherif salem

\begin{abstract}
Having the advantages of high quality and lower amount of materials for hollow core slabs (HCS), the extrusion method is not without its drawbacks because it does not allow shear reinforcement incorporation. However, the strength of HCS against shear stresses is withstood by concrete section only and shear failure of hollow core slab occurs suddenly without large deformation. Therefore, the question is what are the structural benefits of HCS that can be attained by adding shear reinforcements? This paper is concerned with studying the effect of the presence of shear reinforcements on enhancing the structural behavior of the HCS. An experimental study was carried out on 5 full-scale precast pre-stressed modified hollow core slabs specimens (MHCS) subjected to shear loads. Each MHCS panel is comprised of longitudinal, transverse ribs and lower thin slab layer. The spaces between the ribs and the lower concrete layer are filled with polystyrene foam blocks. The results of two specimens were compared with that obtained from a hollow core slab panel having the same dimensions, pre-stressed reinforcement concrete grade and loading scheme. Results indicated that the ultimate shear capacity, failure modes, and load deflection relationships of the proposed slabs are greatly improved by using the suggested technique.
\end{abstract}

